\title{
Schwann-Like Adult Stem Cells Derived From Bone Marrow and Adipose Tissue Express $\gamma$-Aminobutyric Acid Type B Receptors
}

\author{
Alessandro Faroni, ${ }^{1 \star}$ Cristina Mantovani, ${ }^{1}$ Susan G. Shawcross, ${ }^{1}$ Marcella Motta, ${ }^{2}$ \\ Giorgio Terenghi, ${ }^{1}$ and Valerio Magnaghi ${ }^{2}$ \\ ${ }^{1}$ Blond McIndoe Laboratories, Regenerative Biomedicine, The University of Manchester, Manchester, \\ United Kingdom \\ ${ }^{2}$ Department of Endocrinology, Physiopathology and Applied Biology, Università degli Studi di Milano, \\ Milan, Italy
}

$\gamma$-Aminobutyric acid type $B$ receptors (GABA-B) are expressed in glial cells of the central and peripheral nervous systems, and recent evidence has shown their importance in modulating physiological parameters of Schwann cell (SC). SC play essential roles in peripheral nerve regeneration, but several drawbacks prevent their use for nerve repair. Adult stem cells from adipose tissue (ASC) or bone marrow (BM-MSC) can be differentiated into an SC-like phenotype and used as SC replacements. The aim of this study was to investigate GABA-B receptor functional expression in differentiated stem cells by assessing the similarity to SC. By means of RT-PCR and Western blot methodologies, BM-MSC and ASC were found to express both GABA-B1 and GABA-B2 receptor subunits. The expression levels of GABA-B1b and GABA-B2 receptors were influenced by SC-like differentiation, as shown by Western blot studies. GABA-B receptor stimulation with baclofen reduced the proliferation rate of $S C$ and differentiated ASC (dASC) but not that of dBM-MSC. In conclusion, both of the subunits that assemble into a functional GABA-B receptor are present in differentiated stem cells. Furthermore, GABA-B receptors in dASC are functionally active, regulating a key process such as proliferation. The presence of functional GABA-B receptors on differentiated stem cells opens new opportunities for a possible pharmacological modulation of their physiology and phenotype. ๑ 2011 Wiley-Liss, Inc.

Key words: $\gamma$-aminobutyric acid; transdifferentiation; Schwann cells; peripheral nerve regeneration; adult stem cells

In the search of new tools for modulating Schwann cell (SC) physiology, supporting their trophic role in nerve regeneration, much attention has been focused on neurotransmitters, and in particular on $\gamma$-aminobutyric acid (GABA; Magnaghi et al., 2009). GABA is the main inhibitory neurotransmitter in the adult central nervous system and interacts with different receptor types: the ligand-gated ion channel GABA-A and the metabotropic GABA-B receptor. GABA-B receptors belong to the Gprotein-coupled seven-transmembrane receptor family (Kaupmann et al., 1997). Two different subtypes of GABA-B receptors have been cloned; they assemble into a functional heterodimer in the plasma membranes, where they bind extracellular GABA (GABA-B1 subunit) and transmit the signal intracellularly (GABA-B2; Bettler et al., 2004). Moreover, several splice variants of GABA$\mathrm{B} 1$ subunits (that is, $1 \mathrm{a}-1 \mathrm{f}$ ) have been identified (Isomoto et al., 1998; Jones et al., 1998; Kaupmann et al., 1998; White et al., 1998; Pfaff et al., 1999; Schwarz et al., 2000; Wei et al., 2001).

In the peripheral nervous system (PNS), the presence of GABA-B receptors has been demonstrated in autonomic nerve terminals (Bowery et al., 1981); in neonatal rat optic nerve axons (Sun and Chiu, 1999); and in amphibian, mouse, and rat sciatic nerve (Liske and Morris, 1994; Magnaghi et al., 2004, 2008). Furthermore, functional GABA-B receptors are expressed in SC cultures derived from sciatic nerves of neonatal rats (Magnaghi et al., 2004). Interestingly, pharmacological activation of GABA-B receptors decreases SC proliferation in vitro and leads to decreased myelin proteins

Contract grant sponsor: NIHR Manchester Biomedical Research Centre; Contract grant sponsor: Compagnia di San Paolo, Bando Programma Neuroscienze 2008 - Project MOVAG; Contract grant number: 2229/ 2008 (to V.M.); Contract grant sponsor: Association Francaise contre les Myopathies; Contract grant number: 14163/2009 (to V.M.).

${ }^{\star}$ Correspondence to: Alessandro Faroni, Blond McIndoe Laboratories, Regenerative Biomedicine, The University of Manchester, 3.108 Stopford Building, Oxford Road, Manchester, M13 9PT United Kingdom. E-mail: alessandro.faroni@postgrad.manchester.ac.uk

Received 22 December 2010; Revised 1 March 2011; Accepted 2 March 2011

Published online 26 May 2011 in Wiley Online Library (wileyonlinelibrary.com). DOI: 10.1002/jnr.22652 
expression levels, mainly glycoprotein zero (P0) and peripheral myelin protein 22 (PMP22; Magnaghi et al., 2004). Similarly, a comparable effect on P0 and PMP22 expression has been observed in vivo in sciatic nerves of rats treated with the GABA-B agonist baclofen (Magnaghi et al., 2008). In addition, mice lacking GABA-B have been shown to exhibit morphological and molecular changes in peripheral myelin (Magnaghi et al., 2008). These observations suggest that modulating the functional GABAergic receptors present in SC may be a valid approach for regulating important physiological processes such as SC proliferation, differentiation, and peripheral myelination and thus suggest GABAergic drugs as promising factors for management of peripheral nerve damage (Magnaghi et al., 2009).

Interestingly, in the last decade, new findings have shown differentiation of adult stem cells into SC (Tohill and Terenghi, 2004). Bone marrow-derived mesenchymal stem cells (BM-MSC) are isolated from the stromal fraction of the bone marrow (Friedenstein et al., 1974) and can differentiate both in vitro and in vivo into mesenchymal cell types (Barry and Murphy, 2004; Bajada et al., 2008; Garcia-Castro et al., 2008). Another attractive source of stem cells for regenerative medicine is the adipose tissue (Gimble et al., 2007). Like BM-MSC, adipose-derived stem cells (ASC) present important characteristics typical of stem cells, such as extensive selfrenewal capacity and ability to differentiate into multiple lineages (Zuk et al., 2002). Several groups have reported in vitro transdifferentiation of ASC (Kingham et al., 2007; Jiang et al., 2008; Xu et al., 2008; Radtke et al., 2009) and BM-MSC (Dezawa et al., 2001; Caddick et al., 2006; Mahay et al., 2008a; Mantovani et al., 2010) into a glial phenotype. These SC-like stem cells have similar molecular marker expression, morphology, and secretion of growth factors and have been shown to promote nerve regeneration after injury (Tohill et al., 2004; di Summa et al., 2009; Ishikawa et al., 2009).

Differentiated BM-MSC and ASC represent an ideal alternative to $\mathrm{SC}$ in tissue engineering approaches for peripheral nerve repair. Thus, it is of interest to determine whether GABA-B receptors are present on SC-like adult stem cells and whether they could be a potential pharmacological target for modulating cell physiology and regenerative capability.

\section{MATERIALS AND METHODS}

\section{Animals and Cell Cultures}

All the experiments involving animals were carried out in accordance with the U.K. Animals (Scientific Procedures) Act, 1986. Tissues were harvested from the animals following terminal anesthesia with $\mathrm{CO} 2$ and cervical dislocation. For gene and protein expression studies, total RNA or whole-tissue lysates were obtained from fresh frozen brain and liver of adult male Sprague-Dawley rats. For immunohistochemical analyses, sciatic nerves were harvested from adult rats and rapidly fixed in paraformaldehyde.
Neonatal SC cultures. SC were harvested from the sciatic nerves of neonatal Sprague-Dawley rats using a previously established protocol (Mahay et al., 2008a). Cultures were maintained in Dulbecco's modified Eagle's medium (DMEM; Sigma, Poole, United Kingdom) supplemented with 10\% (v/v) fetal bovine serum (FBS; Invitrogen, United Kingdom), 1\% (v/v) penicillinstreptomycin solution (Invitrogen), $14 \mu \mathrm{M}$ forskolin (fsk; Sigma), and $63 \mathrm{ng} \mathrm{ml}^{-1}$ glial growth factor-2 (GGF-2; Acorda Therapeutics Inc., USA). Cells were incubated in $5 \% \mathrm{CO}_{2}$ at $37^{\circ} \mathrm{C}$ and maintained at subconfluent levels on poly-D-lysine (PDL; Sigma)coated $75-\mathrm{cm}^{2}$ flasks, with medium changes every $72 \mathrm{hr}$.

BM-MSC. BM-MSC were isolated from femoral and tibial bone marrow of male adult Sprague-Dawley rats as described previously (Caddick et al., 2006; Mahay et al., 2008a). Cells were cultured in alpha modified Eagle's medium ( $\alpha$ MEM; Sigma) containing 1\% (v/v) penicillin/streptomycin and $10 \%$ FBS. When confluent, cells were passaged with trypsin/ethylenediaminetetraacetic acid (trypsin/EDTA; Invitrogen), split, and replated onto $75-\mathrm{cm}^{2}$ flasks.

ASC. ASC were obtained from subcutaneous visceral and inguinal fat pads as previously described (di Summa et al., 2009; Kingham et al., 2007). After mechanical dissociation and enzymatic digestion, cells were cultured under the same conditions as MSC.

Stem cell differentiation into an SC phenotype. When ASC and BM-MSC cultures were subconfluent, the stem cell growth medium was replaced with fresh medium containing $1 \mathrm{mM} \beta$-mercaptoethanol (Sigma). After $24 \mathrm{hr}$, cells were washed with Hanks balanced salt solution (HBSS; Sigma) and incubated for $72 \mathrm{hr}$ in stem cell growth medium supplemented with $35 \mathrm{ng} \mathrm{ml}^{-1}$ all-trans-retinoic acid (Sigma). The medium was replaced with stem cell differentiation medium containing $5 \mathrm{ng} \mathrm{m}^{-1}$ platelet-derived growth factor (PDGF; Sera Laboratories International), $10 \mathrm{ng} \mathrm{ml}^{-1}$ basic fibroblast growth factor (bFGF; Sera Laboratories International, United Kingdom), $14 \mu \mathrm{M}$ fsk, and $126 \mathrm{ng} \mathrm{m}^{-1}$ GGF-2. Cells were incubated for 2 weeks under these conditions and passaged with trypsin/EDTA when needed, and fresh medium was added approximately every $72 \mathrm{hr}$. Successful differentiation into a glial phenotype and molecular similarities to SC were assessed as previously described (Caddick et al., 2006; Kingham et al., 2007; Mahay et al., 2008a). In detail, immunocytochemical assessments of glial marker expression [that is, S100, glial fibrillary acidic protein (GFAP), and $\mathrm{p} 75$ neurotrophin receptor $\left.\left(\mathrm{p} 75^{\mathrm{NTR}}\right)\right]$ were performed on differentiated BM-MSC (dBM-MSC) and dASC.

\section{RT-PCR}

For each experimental group (SC, BM-MSC, and ASC before and after glial differentiation), cells were collected from confluent cultures by treatment with trypsin/EDTA. The cells and fresh frozen tissues were homogenized, and total RNA was extracted using RNeasy Mini Kit (Qiagen, United Kingdom), according to the manufacturer's protocol. After digestion with DNAse I (Qiagen), RNAse free water (Qiagen) concentrations were determined by UV spectrophotometry; and RTPCR was performed using a One-Step RT-PCR Kit (Qiagen). Briefly, RNA was reverse transcribed for $30 \mathrm{~min}$ at $50^{\circ} \mathrm{C}$, and a 
heating step of $15 \mathrm{~min}$ at $95^{\circ} \mathrm{C}$ was carried out to deactivate the reverse transcriptase and simultaneously activate the DNA polymerase, denaturing the cDNA template. The cDNA was then amplified with the following PCR cycling protocol: denaturation at $95^{\circ} \mathrm{C}$ for $30 \mathrm{sec}$, annealing for $30 \mathrm{sec}$ (number of cycles and optimal temperatures were as per Magnaghi et al., 2004), primer extension at $72^{\circ} \mathrm{C}$ for $1 \mathrm{~min}$, and a final extension step of 5 $\min$ at $72^{\circ} \mathrm{C}$. The following primer sequences were used. For GABA-B1a $\left(35\right.$ cycles with annealing at $\left.60^{\circ} \mathrm{C}\right): 5^{\prime}-$ CTCGGAAGGTTGCCA GATTA- $3^{\prime}$ and $5^{\prime}$-TGTCCATATCCGTCCAGGAG-3'. For GABA-B1b (35 cycles with annealing at $\left.60^{\circ} \mathrm{C}\right)$ : $5^{\prime}$-CTGCC TCTTCTGCTGGTGAT-3' and $5^{\prime}$-TACAGCCAGGCATGA GAATG-3'. For GABA-B2 (35 cycles with annealing at $55^{\circ} \mathrm{C}$ ): $5^{\prime}$-TCCAGTGGAACACGACAGAG-3 ${ }^{\prime}$ and $5^{\prime}$-AGGAGGGT GGTACGTGTCTG-3'. In the case of GABA-B2, a biphasic PCR methodology was performed in order to detect the low-level transcripts. Briefly, after a first round of RT-PCR amplification, the reaction products were reamplified with 30 cycles at $55^{\circ} \mathrm{C}$ using a standard PCR kit (Bioline, United Kingdom). Primers specific for the housekeeping gene $\beta$-actin were used to confirm reverse transcription $\left(35\right.$ cycles at $\left.60^{\circ} \mathrm{C}\right): 5^{\prime}$-CACCACAGCTGAGAGG GAAATCGTGCGTGA-3' and $5^{\prime}$-ATT TGCGGTGCACG ATGGAGGGGCCGGACT-3' ${ }^{\prime}$. As a negative control, a reaction omitting the template was carried out. Brain total mRNA was used as a positive control. In addition, all PCR products were sequenced using a Big Dye Terminator Sequencing Kit (Applied Biosystems, Foster City, CA) to confirm identity by comparison with published sequences (GABA-B1a GeneBank ID: Y10369; GABA-B1b GeneBank ID: Y10370; GABA-B2 GeneBank ID: AJ011318).

\section{Western Blot Analysis}

For protein expression analysis, fresh frozen tissues and cells scraped from confluent cultures were homogenized in lysis buffer containing $100 \mathrm{mM}$ 1,4-piperazinediethanesulfonic acid (PIPES), $5 \mathrm{mM} \mathrm{MgCl}_{2}, 20 \%$ (v/v) glycerol, 0.5\% (v/v) Triton $\mathrm{X}-100,5 \mathrm{mM}$ ethylene glycol tetraacetic acid (EGTA), and a cocktail of protease inhibitors (Sigma). After 15 min of incubation on ice, lysates were freeze-thawed, and protein concentrations were determined by using the Bio-Rad detergent-compatible protein assay. After denaturation for $5 \mathrm{~min}$ at $95^{\circ} \mathrm{C}$ in Laemmli's buffer, $40 \mu \mathrm{g}$ of proteins were separated at $120 \mathrm{~V}$ on $8 \%(\mathrm{w} / \mathrm{v})$ sodium dodecyl sulfate (SDS)-polyacrylamide gels. After electrophoresis, the separated proteins were transferred at $80 \mathrm{~V}$ for $1 \mathrm{hr}$ to nitrocellulose membranes (GE Healthcare, Amersham, United Kingdom). Membranes were stained with Pounceau red (Sigma) in order to confirm successful protein transfer and subsequently blocked for $1 \mathrm{hr}$ in a Tris-buffered saline (TBS)-Tween solution [10 mM Tris, pH 7.5, $100 \mathrm{mM}$ $\mathrm{NaCl}, 0.1 \%(\mathrm{v} / \mathrm{v})$ Tween] with $5 \%(\mathrm{w} / \mathrm{v})$ nonfat dry milk (Marvel). Overnight incubation was performed at $4{ }^{\circ} \mathrm{C}$ using the following primary antibodies diluted 1:500 in blocking buffer: rabbit polyclonal anti-GABA-B1 (Abcam, Bicester, United Kingdom) and guinea pig polyclonal anti-GABA-B2 (Chemicon, United Kingdom). On the following day, membranes were washed and incubated $1 \mathrm{hr}$ with horseradish peroxidaseconjugated antibodies, anti-rabbit $(1: 2,000$; Sigma) or anti- guinea pig (1:50,000; Sigma), for chemiluminescence detection of GABA-B1 and GABA-B2 proteins, respectively. Finally, blots were stripped with a glycine solution $(100 \mathrm{mM}, \mathrm{pH} 2.9$; Sigma) and then reprobed, using a rabbit primary antiserum directed against $\beta$-tubulin $(1: 2,000 ; \mathrm{Abcam})$ as a loading control. Intensity of the signals was analyzed by densitometry using ImageJ64 imaging software (National Institutes of Health).

\section{Immunocytochemistry}

For immunocytochemical studies, cells from each experimental group were plated on chamber slides (Nunc-Fisher Scientific, Pittsburgh, PA) at a density of $4 \times 10^{4}$ cells per chamber. After $24 \mathrm{hr}$ of incubation, slides were fixed for $20 \mathrm{~min}$ in $4 \%(\mathrm{w} / \mathrm{v})$ paraformaldehyde (PFA; Sigma) in water and washed in phosphate buffer solution (PBS). Cells were permeabilized with $0.2 \%(\mathrm{v} / \mathrm{v})$ Triton X-100 for $30 \mathrm{~min}$ at room temperature and blocked for $1 \mathrm{hr}$ with normal goat and donkey serum solution (both 1:100; Sigma). The following primary antibodies were applied overnight at $4^{\circ} \mathrm{C}$ : for GABA-B1 (rabbit polyclonal 1:300; Abcam), GABA-B2 (guinea pig polyclonal 1:300; Chemicon), S100 (rabbit polyclonal 1:500; Dako, Carpinteria, CA), GFAP (mouse monoclonal 1:500; Thermo Scientific, United Kingdom), and p $75^{\text {NTR }}$ (rabbit polyclonal 1:300; Promega, United Kingdom). On the following day, slides were rinsed in PBS before incubation in goat anti-rabbit FITC (Vector Laboratories, Peterborough, United Kingdom)-, goat anti-guinea pig FITC (Vector Laboratories)-, or horse anti-mouse FITC (Vector Laboratories)-conjugated secondary antibodies, depending on the host species of the primary antibodies. For colocalization studies of GABA-B receptor subunits, the following secondary antibodies were used: goat anti-rabbit Texas red (for GABA-B1; Vector Laboratories) and goat anti-guinea pig FITC (for GABA-B2; Vector Laboratories). After final washing with PBS, slides were mounted using Vectashield mounting medium for fluorescence containing 4',6-diamidino-2-phenylindole (DAPI) for nuclear staining (Vector Laboratories). Finally, images were acquired using a fluorescence microscope (Olympus BX60) and processed in ImageJ64 imaging software.

To confirm antibody specificity, immunohistochemical analysis was performed on frozen cross-sections of sciatic nerves from adult Sprague-Dawley rats. Tissues were rapidly harvested and fixed overnight at $4{ }^{\circ} \mathrm{C}$ in $4 \%(\mathrm{w} / \mathrm{v})$ PFA in PBS. Fixed tissues were cryoprotected in $15 \%(\mathrm{w} / \mathrm{v})$ sucrose, $0.1 \%(\mathrm{w} / \mathrm{v})$ sodium azide in PBS and embedded in TissueTek O.C.T. (optimal cutting temperature) compound (Thermo Scientific). Fifteen-micrometer-thick sections of sciatic nerves were cut and collected onto glass slides coated with Vectabond reagent (Vector Laboratories) to prevent section detachment. Slides were dried overnight at $37^{\circ} \mathrm{C}$ and then stained as described for cell cultures.

\section{Proliferation Assessments}

To assess cell proliferation, a 3-(4,5-dimethyl-2-thiazolyl)-2,5-diphenyl-2H-tetrazolium bromide (MTT; Sigma) assay was performed. SC, dBM-MSC, and dASC were seeded at density of $2 \times 10^{4}$ cells/well onto six-well plates (Corning Inc., Corning, NY) and incubated in their growth medium (GM) containing growth factors. Plates were previously PDL- 
coated for assessment of SC proliferation. After $24 \mathrm{hr}$ of incubation at $37^{\circ} \mathrm{C}$ and $5 \% \mathrm{CO} 2$, the medium was replaced with fresh GM supplemented with $10 \mu \mathrm{M}$ fsk (Sigma) in the presence or absence of the selective GABA-B receptor agonist baclofen (bac; $100 \mu \mathrm{M}$; Sigma). Cells were grown under these conditions, and fresh drugs were added every $24 \mathrm{hr}$. After 6 days of treatments, cells were rinsed with sterile PBS and incubated at $37^{\circ} \mathrm{C}$ with $1 \mathrm{mg} / \mathrm{ml} \mathrm{MTT}$ in PBS. After $24 \mathrm{hr}$ of incubation, the purple formazan crystals, formed at the bottom of the well, were dissolved with $0.04 \mathrm{~N} \mathrm{HCl}$ in isopropanol. Absorbances of the dyed solutions were recorded at 570 $\mathrm{nm}$ with an Asys UVM-340 microplate reader/spectrophotometer (Biochrom Ltd., United Kingdom). Data were expressed as a percentage of the values detected in controls (cells grown with only fsk). Three separate experiments were performed in triplicate, for nine total determinations for each experimental group.

\section{Statistical Analysis}

Statistical significance for the Western blot and proliferation studies was estimated by unpaired two-tailed Student's $t$-test in GraphPad Prism 5 (GraphPad Software, Williston, VT). In Western blot studies, densitometry data of GABA-B subunits were normalized to the levels of $\beta$-tubulin used as a loading control. All data were expressed as mean \pm SEM. Levels of significance were expressed as $P$ values vs. controls $\left(\star P<0.05,{ }^{\star} \star P<0.01\right)$.

\section{RESULTS}

\section{Stem Cell Differentiation Into Glial Phenotype}

BM-MSC and ASC were successfully trans-differentiated in vitro into a glial phenotype by following a previously described protocol (Dezawa et al., 2001; Kingham et al., 2007). After 2 weeks of differentiation in vitro, the majority of both adult stem cell groups showed obvious morphological changes and exhibited the splindle-like shape typical of neonatal SC. Stem cell differentiation into an SC-like phenotype was confirmed with immunocytochemical assessments of glial marker expression as previously described (Caddick et al., 2006; Kingham et al., 2007; Mahay et al., 2008a). dASC and dBM-MSC showed positive immunocytochemical staining for the glial markers S100, GFAP, and $\mathrm{p} 75^{\mathrm{NTR}}$, which confirmed the morphological and molecular similarities of these cells to neonatal SC used as a positive control (Fig. 1).

\section{Assessment of GABA-B Receptor mRNA Expression}

The presence of GABA-B-specific transcripts was assessed by means of qualitative RT-PCR. With specific primers, two amplicons of 197 and 349 bp corresponding to $\mathrm{mRNAs}$ encoding for GABA-B1 receptor isoforms (B1a and $\mathrm{B} 1 \mathrm{~b}$, respectively) were detected in all the experimental groups (uBM-MSC, dBM-MSC, uASC, and dASC) and in the positive controls (brain and SC; Fig. 2).
After a first round of PCR amplification, it was not possible to identify mRNA transcripts for GABA-B2 receptor, probably because of low template transcript levels (data not shown). However, amplicons corresponding to GABA-B2 receptor mRNA (amplicon size $210 \mathrm{bp}$ ) were detected after a second round of PCR amplification in uBM-MSC, dBM-MSC, and dASC and in the positive controls (SC and brain), but not in uASC (Fig. 2).

Primers specific for the housekeeping gene $\beta$-actin (product size $510 \mathrm{bp}$ ) were used as a loading control and for quality assessment of the extracted mRNAs. A reaction with the omission of the template was carried out as a negative control, and no amplicons were detected. In all PCR studies, brain and SC total mRNAs were used as positive controls. Moreover, at the end of electrophoretic separation, PCR products were extracted from the gel, purified, and sequenced to verify their identity by comparison with published sequences (GABA-B1a GeneBank ID: Y10369; GABA-B1b GeneBank ID: Y10370; GABA-B2 GeneBank ID: AJ011318). All amplicons were sequenced in the forward and reverse directions to ensure complete sequence determination. The sequences obtained were input into the The National Center for Biotechnology (NCBI; http://blast.ncbi.nlm.nih.gov/) website and subjected to the Basic Local Alignment Search Tool (BLAST) with blastn and Megablast algorithms in order to find similarities to available nucleotide databases. At least $98 \%$ of identity with published sequences of GABA-B1a, GABA$\mathrm{B} 1 \mathrm{~b}$, and GABA-B2 was found for all the amplicons sequenced.

\section{Identification of GABA-B Receptor Protein Expression}

To investigate GABA-B1 receptor isoform expression at the protein level, a Western blot analysis was performed on whole-cell protein lysates. Using an antibody directed against both the isoforms of GABA-B1 receptor splice variants, two bands of 130 (GABA-B1a) and 100 $\mathrm{kDa}$ (GABA-B1b) were detected in all adult stem cells groups as well as in SC and brain lysates used as positive controls (Fig. 3A). GABA-B1a isoform protein expression was not significantly different in undifferentiated and differentiated adult stem cells (data not shown) or in the control groups. Interestingly, GABA-B1b receptor subunit was found to be up-regulated in both dBM-MSC and dASC $(P<0.05$; Fig. 3B). An antibody raised against the housekeeping gene protein $\beta$-tubulin was used as a loading control, resulting in a specific band of $50 \mathrm{kDa}$. Moreover, in the search for a negative control, Western blot analysis was also performed on whole protein tissue lysates from liver. A signal for GABA-B1b receptor isoform, but not for GABA-B1a, was detected in the liver sample, confirming published data obtained from photoaffinity labelling experiments (Belley et al., 1999; Fig. 3A).

GABA-B2 receptor subunit expression was assessed by Western blot analysis. Similarly to the Western blot analysis described for GABA-B1 isoforms, an antibody raised against GABA-B2 receptor subunit revealed a spe- 

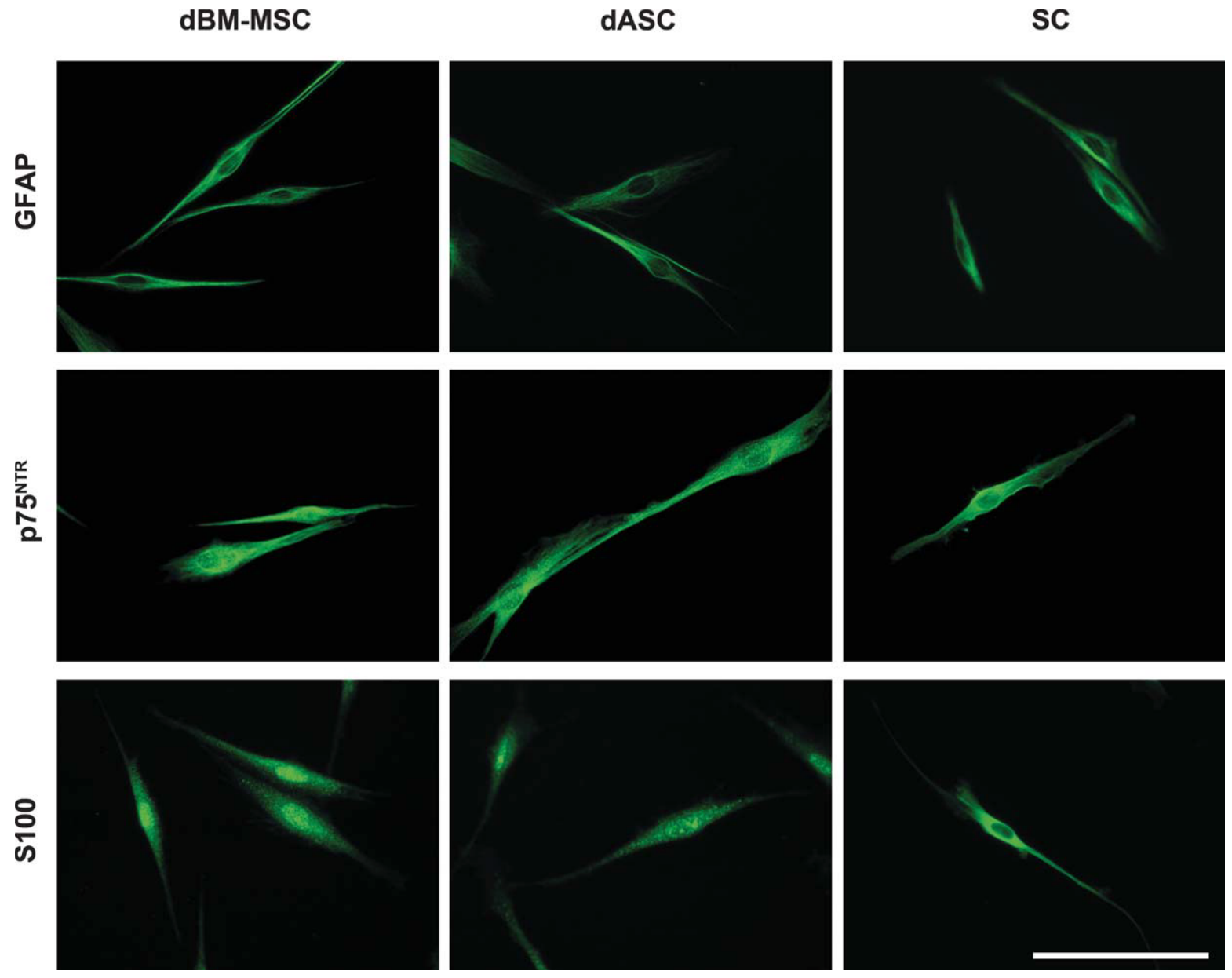

Fig. 1. Glial marker expression. After 2 weeks of differentiation into a glial phenotype, dBMMSC and dASC were found to express the glial markers GFAP, $75^{\mathrm{NTR}}$, and S100, with patterns similar to those observed in SC used as a positive control. Scale bar $=100 \mu \mathrm{m}$. [Color figure can be viewed in the online issue, which is available at wileyonlinelibrary.com.]

cific band of $\sim 120 \mathrm{kDa}$ in all the cell lysates analyzed (Fig. 3A). The GABA-B2 receptor subunit was found to be up-regulated in BM-MSC following glial differentiation, whereas down-regulation of protein levels was observed after SC-like differentiation of ASC $(P<0.05$, Fig. 3C). Brain and SC whole-cell lysates were used as positive controls, and the housekeeping gene protein $\beta$-tubulin was used as a loading control. No signal was detected in liver lysate used as a negative control.

\section{GABA-B Receptors Localization in Adult Stem Cells}

To investigate the cellular localization of GABA-B receptors further, undifferentiated and differentiated adult stem cells were stained with specific antibodies for GABA-B1 and GABA-B2 subunits. An antibody raised against both the isoforms of GABA-B1 receptor was used for immunocytochemical studies on undifferentiated and differentiated stem cells as well as SC and sciatic nerves (used as positive controls). Both uBM-MSC and
uASC showed positive GABA-B1 immunostaining, with a similar pattern of cytoplasmic distribution (Fig. 4A,B). Moreover, the same pattern of expression was observed in SC cultures used as positive controls (Fig. 4E) and in SC wrapping the axons in sciatic nerve cross-sections (Fig. 4F). As negative controls, stainings with the omission of primary antibodies were performed and did not show immunopositivity (data not shown).

As described for GABA-B1, immunocytochemical analysis of GABA-B2 receptor was performed on both undifferentiated and differentiated adult stem cells as well as sciatic nerves; SC cultures were used as positive controls. Undifferentiated and differentiated stem cells showed positive staining for GABA-B2 with a pattern similar to that of neonatal SC (Fig. 5). As observed for GABA-B1, GABA-B2 receptors were localized in the cytoplasm in all cells groups analyzed. Immunostaining with the omission of primary antibody was performed as a negative control and revealed no staining (data not shown).

To confirm colocalization of GABA-B1 and GABA-B2 subunits, an essential requirement for recep- 


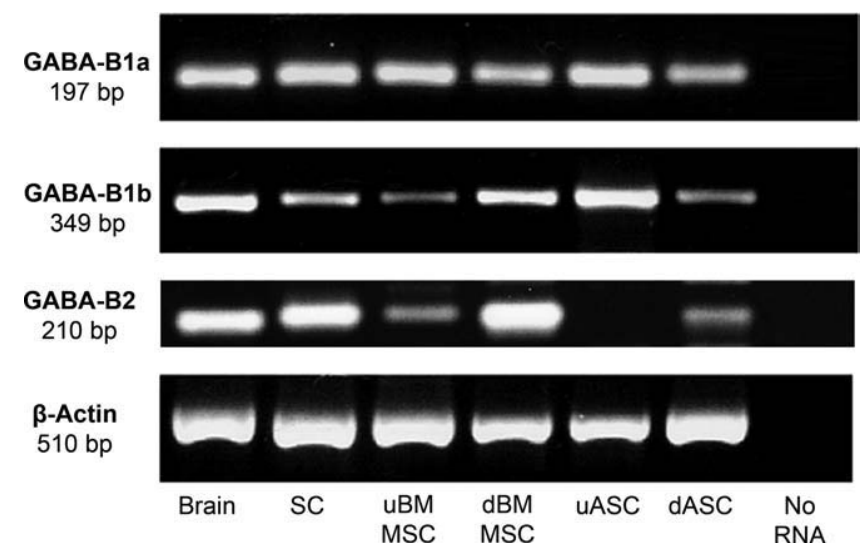

Fig. 2. Qualitative RT-PCR for GABA-B receptors trancripts. mRNA transcripts for both isoforms of GABA-B1 receptor, GABA$\mathrm{B} 1 \mathrm{a}$ and GABA-B1b, were present in all experimental groups analyzed and in the positive controls. After two rounds of PCR amplification, GABA-B2 mRNA transcripts were detected in all the experimental groups, with the exception of uASC. Brain and SC total mRNAs were used as positive controls. All amplicons were sequenced, and identity with published GABA-B receptors mRNA sequences was shown. A negative control with template omission was included, and $\beta$-actin was used as an RNA quality and loading control.

tor function, double immunostaining was performed in differentiated stem cells. In both dBM-MSC and dASC, GABA-B1 and GABA-B2 were shown to colocalize, suggesting that a functional GABA-B heterodimer might be assembled in differentiated stem cells (Fig. 6A).

\section{Assessment of Proliferation}

One of the reported effects of GABA-B receptor stimulation in SC culture is the progressive decrease of fsk-induced proliferation observed after 6 days of treatment in vitro with a specific GABA-B receptor agonist (bac; Magnaghi et al., 2004). To assess GABA-B receptor functionality, dBM-MSC and dASC cultures were exposed to $10 \mu \mathrm{M}$ fsk in the presence or absence of 100 $\mu \mathrm{M}$ bac. As a positive control, the same treatments were performed on neonatal SC cultures. After 6 days of treatment, an MTT assay was performed to assess cell proliferation. Similar to previously published results (Magnaghi et al., 2004), bac treatments were shown to reduce the proliferation rate of SC compared with cells grown only in presence of $10 \mu \mathrm{M}$ fsk. The proliferation decrease in bac-treated SC samples (decrease of $31.50 \%$ $\pm 9.70 \%$ vs. fsk $)$ was statistically significant $(P<0.01$; Fig. 6B). In the same way, GABA-B receptor stimulation with bac reduced the proliferation of dASC (decrease of $23.58 \% \pm 6.50 \%$ vs. fsk, $P<0.01$; Fig. 6). However, there was no effect on the proliferation rate of dBM-MSC following treatments with bac (Fig. 6B).

\section{DISCUSSION}

In this study, we investigated the presence of GABA-B receptors in BM-MSC and ASC differentiated into an SC-like phenotype. GABA-B receptor expression of differentiated stem cells was compared with the expression in SC derived from neonatal rats sciatic nerves, which are known to express functional GABA-A and $-\mathrm{B}$ receptors (Magnaghi et al., 2004, 2006). The same molecular characterization for GABA-B receptor was performed also on SC cultures obtained from sciatic nerves of adult rat, without showing any differences (unpublished data). Interestingly, pharmacological activation of GABA-B receptors decreases the proliferation of neonatal SC in vitro and leads to decreased myelin protein expression levels (Magnaghi et al., 2004). Similarly, a comparable effect on expression of myelin proteins has been observed in vivo, in the sciatic nerve of rats treated with the GABA-B agonist bac (Magnaghi et al., 2008). In addition, mice lacking GABA-B receptors have been shown to exhibit morphological and molecular changes in peripheral myelin (Magnaghi et al., 2008). These observations suggest that modulating the functional GABAergic receptors present in SC may be a valid approach for regulating important physiological processes such as SC proliferation, differentiation, and peripheral myelination and thus suggest GABAergic drugs as promising factors for management of peripheral nerve damage (Magnaghi et al., 2009).

Over the last few decades, much of the attention in the field of peripheral nerve regeneration has been focused on the use of adult stem cells as an SC alternative in regenerative medicine approaches (Terenghi et al., 2009). The first protocols used to induce adult stem cell transdifferentiation into neuronal and glial phenotypes resulted in a rapid and reversible induction using cytotoxic agents in serum-free media (Sanchez-Ramos et al., 2000; Woodbury et al., 2000). However, this short-term and temporary induction of neuronal phenotype and morphology has been attributed to the cytotoxic effect of the chemicals, which causes a rapid cytoskeletal rearrangement and cell shrinkage, rather than to a proper, stable transdifferentiation (Lu et al., 2004; Neuhuber et al., 2004). By contrast, ours group and others have achieved a long-term differentiation of adult stem cells (both BM-MSC and ASC) into a glial phenotype with a combination of chemical agents and growth factors (Dezawa et al., 2001; Caddick et al., 2006; Kingham et al., 2007; Jiang et al., 2008; Xu et al., 2008). By means of in vitro and in vivo studies, the differentiated SC-like cells obtained through this protocol have been shown to possess morphological, molecular, and functional similarities to SC (Dezawa et al., 2001; Tohill et al., 2004; Caddick et al., 2006; Kingham et al., 2007; Jiang et al., 2008; Mahay et al., 2008a; Xu et al., 2008; di Summa et al., 2009; Ishikawa et al., 2009; Mantovani et al., 2010).

In this work, BM-MSC and ASC were successfully harvested and differentiated into an SC-like phenotype, as previously described (Tohill et al., 2004; Kingham et al., 2007). Differentiation into an SC-like phenotype was confirmed by assessment of glial marker expression (S100, GFAP, and $\mathrm{p} 75^{\mathrm{NTR}}$ ) by immunocytochemistry 
A

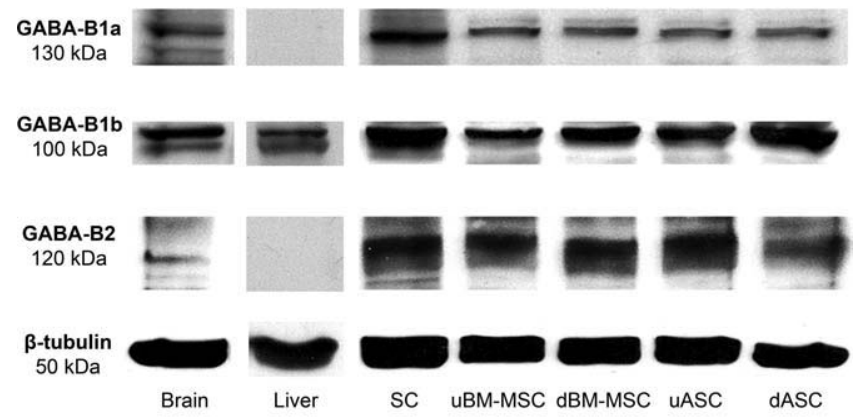

B

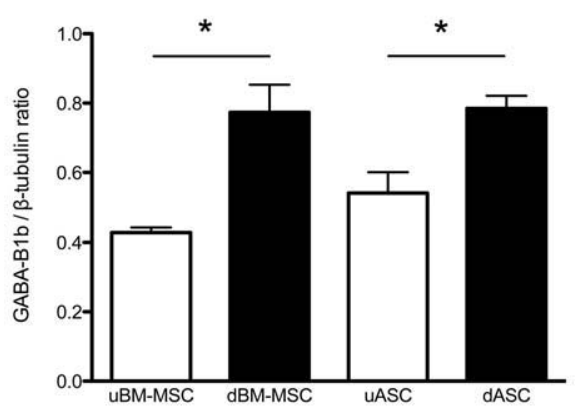

C

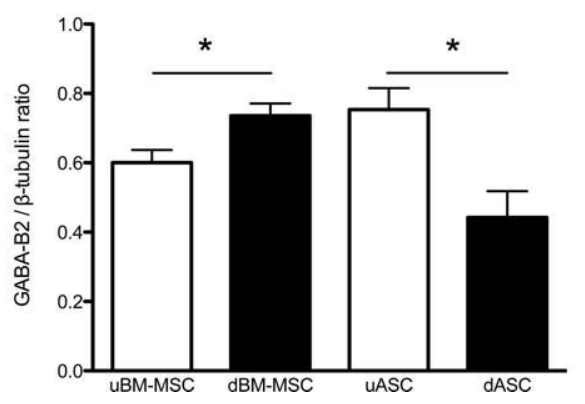

Fig. 3. Western blot analysis of GABA-B receptors. A: Both splice variants of GABA-B1 receptor proteins were detected in all adult stem cell groups and in the positive controls (brain and SC). GABA$\mathrm{B} 1 \mathrm{~b}$, but not GABA-B1a, was detected in liver protein lysate. Western blot analysis on whole-cell and tissue lysates showed the presence of GABA-B2 receptor protein $(\sim 120 \mathrm{kDa})$ in all adult stem cell groups and in the positive controls (brain and SC). B: After stem cell differentiation into SC-like cells, GABA-B1b protein expression was significantly up-regulated in both BM-MSC and ASC $\left({ }^{*} P<0.05\right)$. C: GABA-B2 protein levels were increased in BM-MSC after SClike differentiation $\left({ }^{*} P<0.05\right)$, whereas down-regulation was observed in dASC $(* P<0.05)$. Signal for GABA-B2 was not detected in liver lysate, which was used as negative control. $\beta$-Tubulin $(50 \mathrm{kDa})$ was used as a loading control.

and comparison with SC as positive control. Therefore, bone marrow and adipose tissue represent an attractive source of adult stem cells that can be differentiated into a glial phenotype and used as SC substitutes to promote nerve regeneration after injury (Tohill et al., 2004; di Summa et al., 2009). Furthermore, the possibility of modulating the physiology of differentiated adult stem cells by acting on functional receptors, including a putative GABA-B, might represent an important biological and pharmacological tool in peripheral nerve repair strat- egies. Thus, the intended purpose of this study is the investigation of a new tool for a putative pharmacological manipulation of stem cell physiology and not the assessment of already established molecular similarities with SC.

The presence of GABA-B receptor in adult stem cells has been poorly investigated. However, there is evidence that GABA is present in murine ASC after neuronal-glial differentiation (Safford et al., 2004). Furthermore, functional GABA-B receptors were found in neuronal-like BM-MSC (Marcoli et al., 2008). Rodent and human BMMSC have been induced into a neuronal phenotype with the aim of using them in the treatment of neurological disease (Woodbury et al., 2000). The data we present here show that both BM-MSC and ASC express all the subunits (that is, GABA-B1a, -B1b, and -B2) that could assemble into a functional heterodimer. The differentiation of adult stem cells into a glial phenotype increased the expression levels of GABA-B1b receptor subunit in both BMMSC and ASC. Similarly to our observations after glial differentiation, the neuronal differentiation of BM-MSC was reported to increase GABA-B1 mRNA levels (Marcoli et al., 2008). GABA-B1a protein expression levels were not modified following SC-like differentiation. This should be expected, because GABA-B1a and GABA-B1b subunits are independently regulated at the transcriptional level (Pinard et al., 2010). Interestingly, liver tissue lysates showed positivity for GABA-B1b, but not GABA-B1a, in Western blot experiments. This result, in contrast with other data using liver as negative control (Kaupmann et al., 1997), confirms previously published photoaffinity studies in which GABA-B1b, but not GABA-B1a, was detected in liver lysates (Belley et al., 1999).

RT-PCR studies were performed to assess also the presence of GABA-B2 mRNA transcripts. After the first amplification step, the specific amplicons for GABA-B2 were not detected, probably because of low template levels. Further amplification of the products of the first reaction revealed specific transcripts in uBM-MSC, dBM-MSC, and dASC and in the positive controls, but not in uASC. GABA-B2 receptor expression at the protein level was assessed by Western blot analysis on whole-cell lysates. SC and uBM-MSC, uASC, dBMMSC, and dASC were found to express GABA-B2 receptor protein. Interestingly, the GABA-B2 receptor subunit was found in uASC at the protein level. In addition, differentiation of ASC into an SC-like phenotype decreased the levels of GABA-B2 receptor protein. These data are in contrast to RT-PCR results. However, the different expression revealed with RT-PCR and Western blot analysis in ASC might be due to a more rapid turnover of GABA-B2 mRNA compared with GABA-B2 protein. Moreover, the two steps of amplification carried out to detect GABA-B2 mRNA transcripts might have further affected the quantitative meaning of the data.

Western blot data for dASC showed up-regulation of GABA-B1b and down-regulation of GABA-B2 receptor subunits. However, the colocalization of B1 and 

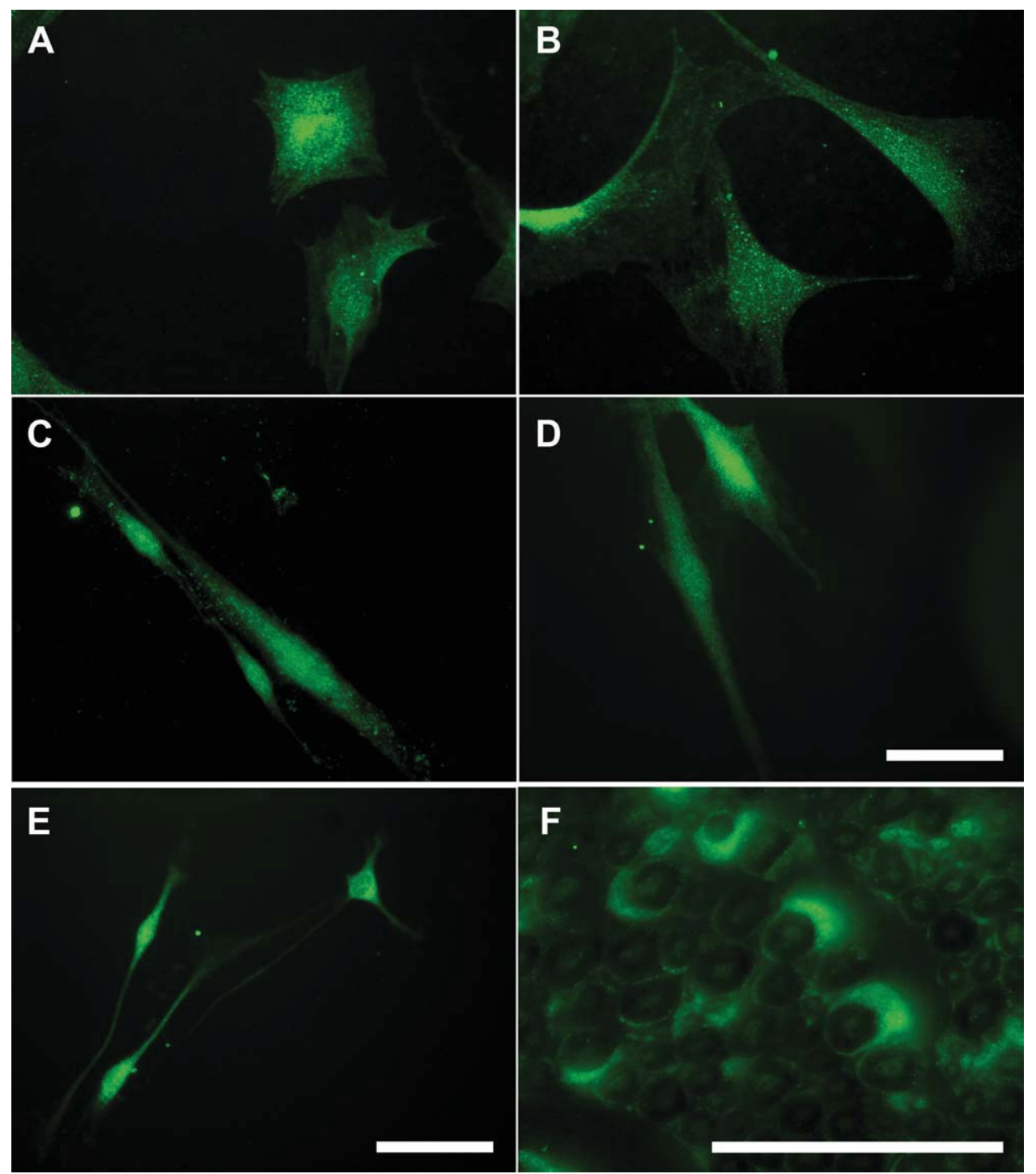

Fig. 4. Immunostaining for GABA-B1 receptors. Undifferentiated bone marrow (A) and adipose $(\mathbf{B})$ stem cells were immunopositive for GABA-B1 receptor (FITC, green), with similar patterns of cytoplasmic distribution. No changes were observed in the receptor localization in differentiated bone marrow $(\mathbf{C})$ and adipose $(\mathbf{D})$ stem

B2 subunits, together with the decrease in proliferation following bac treatment, suggests the formation of a functional heterodimer in dASC. In the broadly accepted heterodimeric model of GABA-B receptors, one of the GABA-B1 isoforms assemble with GABA-B2 to generate $\mathrm{GABA}-\mathrm{B}(1 \mathrm{a}, 2)$ and $\mathrm{GABA}-\mathrm{B}(1 \mathrm{~b}, 2)$ receptors. In this model, GABA-B1 subunits are responsible for ligand binding and coupling with effector systems, whereas GABA-B2 is involved in the trafficking of the heterodimer to the plasma membrane (Bettler et al., 2004). Despite the down-regulation of dASC observed, GABA-B2 protein levels might still be adequate to guarantee the correct trafficking of the functional heterodimer to the plasma membrane. Moreover, desensitized GABA-B receptors undergo rapid constitutive internalization, followed by fast recycling

cells. SC cultures (E) and rat sciatic nerve cross-sections (F) were used as positive control and showed positive staining. Scale bars = $50 \mu \mathrm{m}$. [Color figure can be viewed in the online issue, which is available at wileyonlinelibrary.com.]

of reactivated receptor in the plasma membrane, with about $40-50 \%$ of the endocytosed receptors recycled back to the plasma membrane within 15 min (Benke, 2010). On the basis of this mechanism, it is reasonable to speculate that the levels of GABA-B2 protein found in dASC are adequate to maintain a functional concentration of the heterodimer on the cell surface.

We have demonstrated here that both the subunits required to form a functional GABA-B receptor are expressed and colocalize in SC-like differentiated adult stem cells. This may represent an exploitable pharmacological advantage for tuning stem cell physiology. The successful coupling of GABA-B receptors with an inhibitory downstream signaling pathway has been previously described for SC (Magnaghi et al., 2004). In particular, 

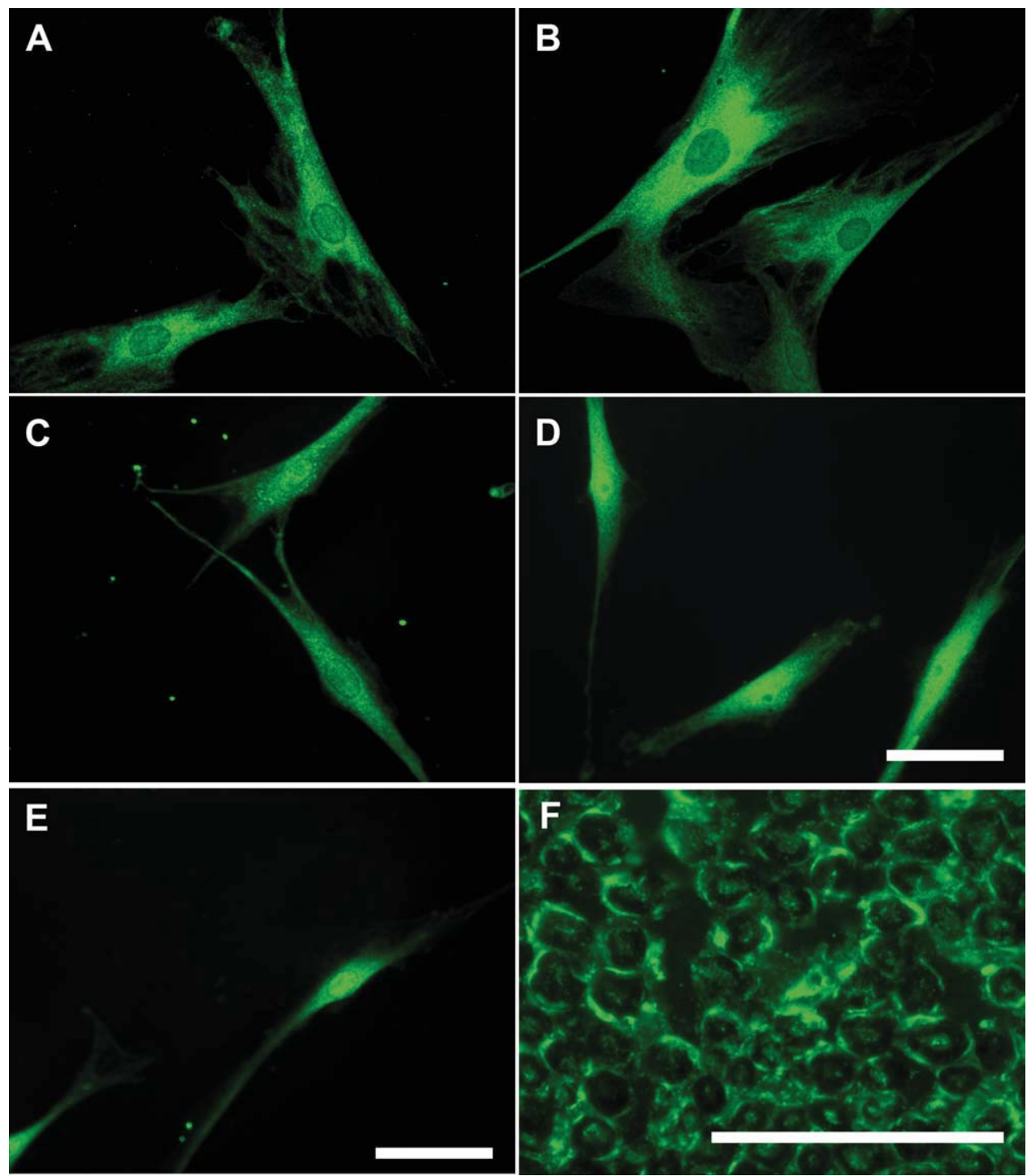

Fig. 5. Immunostaining for GABA-B2 receptors. Undifferentiated bone marrow $(\mathbf{A})$ and adipose $(\mathbf{B})$ stem cells showed positive staining (FITC, green) for GABA-B2 receptor. dBM-MSC (C) and dASC (D) showed similar immunopositivity diffused in the cytoplasm. No changes in GABA-B2 receptor localization were observed following

pharmacological activation of GABA-B receptors in SC leads to changes in cAMP levels and progressively decreases the proliferation rate of SC in a dose-dependent manner (Magnaghi et al., 2004). The function of GABA-B receptors in adult stem cells has also been poorly investigated. However, negative coupling of GABA-B receptors with the adenylate cyclase system has been reported in BM-MSC differentiated into a neuronal phenotype (Marcoli et al., 2008). Moreover, there is evidence of a GABA-mediated effect on stem cell proliferation in adult stem cell niches (Liu et al., 2005; Young and Bordey, 2009). To assess receptor function, the GABA-B receptors on stem cells were stimulated with a specific agonist (bac), and the effect on proliferation was the differentiation into an SC-like phenotype. SC cultures $(\mathbf{E})$ and rat sciatic nerve cross-sections $(\mathbf{F})$ were used as positive control and showed positive staining. Scale bars $=50 \mu \mathrm{m}$. [Color figure can be viewed in the online issue, which is available at wileyonlinelibrary. com.]

evaluated. As previously reported (Magnaghi et al., 2004), 6 days of treatment with bac was able to reduce significantly the SC proliferation induced by fsk. Moreover, the same effect on cell proliferation was observed in dASC treated with bac, further confirming the functional similarity of SC-like ASC to SC. However, GABA-B receptor stimulation under the same experimental conditions does not seem to affect the proliferation of BM-MSC differentiated in SC-like cells. The difference in cell response to GABA-B receptor stimulation could result from a different physiological role for the receptor in dBM-MSC compared with dASC. Furthermore, the interaction of GABA-B receptor subunits with other intracellular proteins might affect the success- 
A

\section{dASC}
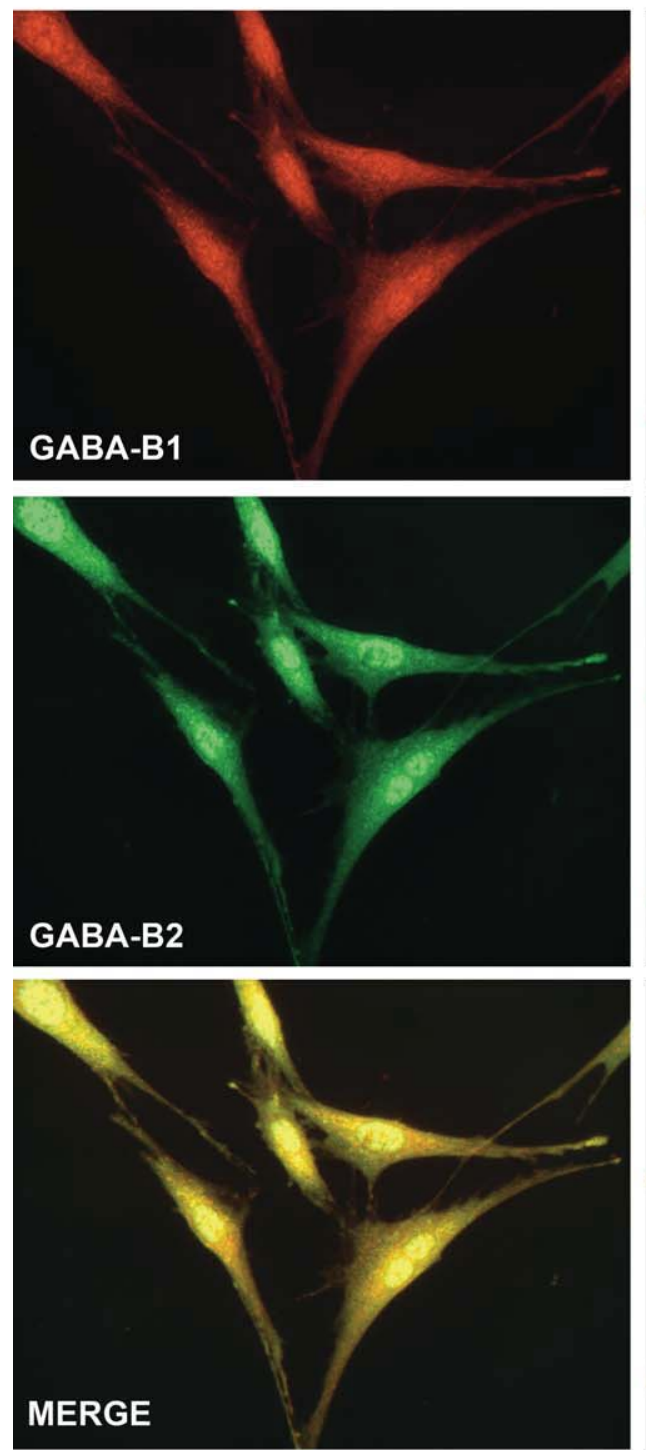

dBM-MSC
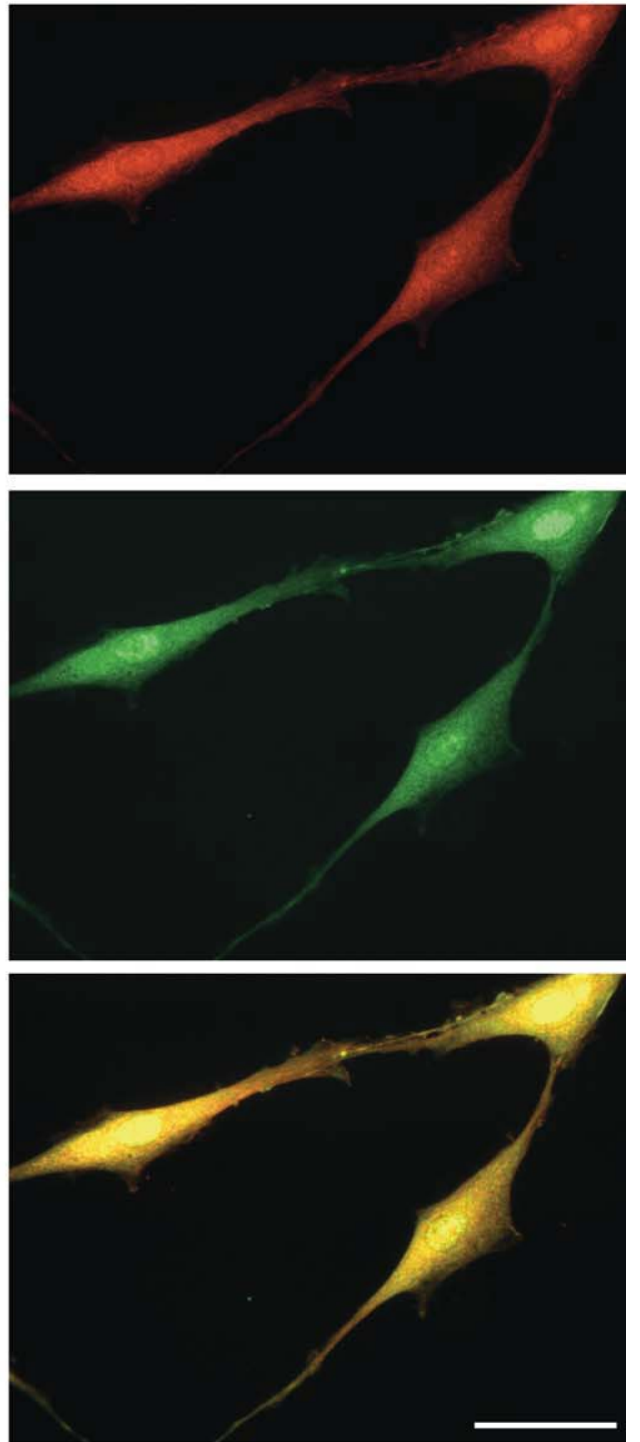

B

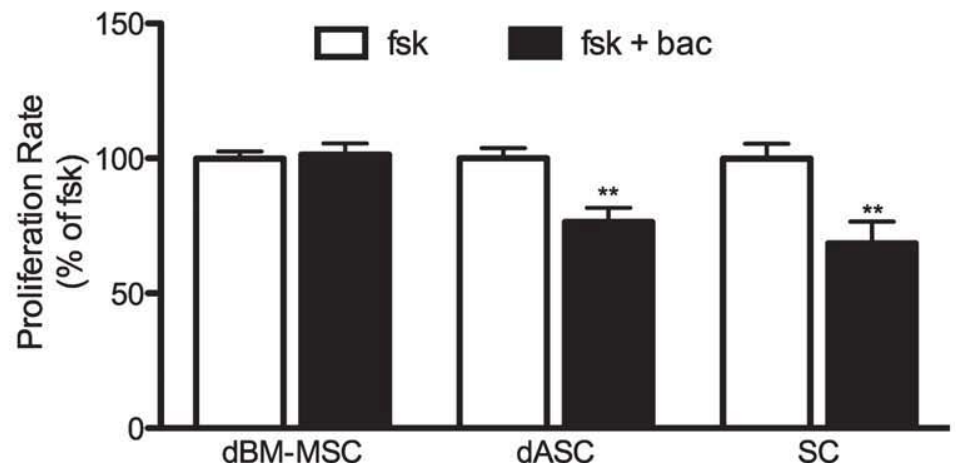

Fig. 6. GABA-B receptor function. GABA-B1 and GABA-B2 receptor subunits colocalize in $\mathrm{dBM}-\mathrm{MSC}$ and $\mathrm{dASC}$ (yellow in the merged images; A), suggesting the formation of a functional heterodimer. Proliferation rate after 6 days of treatment with the GABA-B receptor-specific agonist baclofen (bac) was assessed by MTT assay
(B). GABA-B receptor stimulation with baclofen significantly reduced the proliferation rate of dASC (decrease of $23.58 \% \pm 6.50$ vs. fsk, ${ }^{* *} P<0.01$ ) and of SC (decrease of $31.50 \% \pm 9.70$ vs. fsk, $* * P<0.01)$ but not of dBM-MSC. Scale bar $=50 \mu \mathrm{m}$. 
ful formation of a functional heterodimer in dBM-MSC, or it could modulate GABA-B receptor trafficking and targeting to the plasma membrane (Couve et al., 2001). The observed heterogeneity of GABA receptors probably is due to differences in subunit distribution, coupling efficiency, receptor phosphorylation, or effector diversity as well as to interaction with a family of recently discovered auxiliary proteins that seems to be responsible for much of the observed diversity in native GABA responses (Pinard et al., 2010). Taken together, these observations might provide an explanation for the different response observed between $\mathrm{dBM}-\mathrm{MSC}$ and dASC after GABA-B receptor stimulation. Although ASC and BM-MSC share more than $90 \%$ of phenotypic markers, differences in surface protein expression have been reported (Gimble et al., 2007). Whereas the harvest of MSC from bone marrow is a highly invasive procedure (Locke et al., 2009), adipose tissue can easily be isolated by conventional liposuction procedures under local anesthesia (Kingham et al., 2007). Furthermore, from adipose tissue it is possible to obtain a greater number of stem cells than from the bone marrow (Strem et al., 2005), and, compared with BM-MSC, ASC are easier to culture for longer periods and also show faster growth rates (Kingham et al., 2007; Locke et al., 2009). Given the proposed aim of improving the regenerative capability of differentiated stem cells, the bac-induced decrease in dASC proliferation might seem controversial. However, different pharmacological approaches (that is, GABA agonists or antagonist) might be used to modulate stem cell physiology.

Taken together, the data presented here confirm the previously reported expression of GABA-B receptor subunits in cultures of SC (Magnaghi et al., 2004). Furthermore, GABA-B receptor mRNAs and proteins are present in both BM-MSC and ASC differentiated into an SC-like phenotype. Interestingly, GABA-B1 and GABA-B2 subunits present in dASC assemble into a functional GABA-B receptor able to modulate stem cell proliferation. It might be of interest to assess whether stimulation of the functional GABA-B receptors is able to modulate the effect on neurite outgrowth, neurotrophic factors, and myelin protein expression, in previously established in vitro cocolture systems with motor or sensory neurons (Kingham et al., 2007; Mahay et al., 2008b; Mantovani et al., 2010). Although further studies are required to understand the physiological role of the GABA-B receptor in adult stem cells, the presence of the receptors suggests a new pharmacological target for modulating the physiology of differentiated adult stem cells and improving their performance in promoting nerve regeneration after injury.

\section{ACKNOWLEDGMENTS}

The authors are grateful to Acorda Therapeutics, USA, for generously supplying GGF-2 for the continuation of this work. We also thank Ms Marinella Ballabio for excellent technical assistance and The University of Manchester DNA sequencing facility for sequence data. A.F. was funded by a fellowship awarded from Università degli Studi di Milano.

\section{REFERENCES}

Bajada S, Mazakova I, Richardson JB, Ashammakhi N. 2008. Updates on stem cells and their applications in regenerative medicine. J Tissue Eng Regen Med 2:169-183.

Barry FP, Murphy JM. 2004. Mesenchymal stem cells: clinical applications and biological characterization. Int J Biochem Cell Biol 36:568-584.

Belley M, Sullivan R, Reeves A, Evans J, O’Neill G, Ng GY. 1999. Synthesis of the nanomolar photoaffinity $\mathrm{GABA}_{\mathrm{B}}$ receptor ligand CGP 71872 reveals diversity in the tissue distribution of $\mathrm{GABA}_{\mathrm{B}}$ receptor forms. Bioorg Med Chem 7:2697-2704.

Benke D. 2010. Mechanisms of $\mathrm{GABA}_{\mathrm{B}}$ receptor exocytosis, endocytosis, and degradation. Adv Pharmacol 58:93-111.

Bettler B, Kaupmann K, Mosbacher J, Gassmann M. 2004. Molecular structure and physiological functions of $\mathrm{GABA}_{\mathrm{B}}$ receptors. Physiol Rev 84:835-867.

Bowery NG, Doble A, Hill DR, Hudson AL, Shaw JS, Turnbull MJ, Warrington R. 1981. Bicuculline-insensitive GABA receptors on peripheral autonomic nerve terminals. Eur J Pharmacol 71:53-70.

Caddick J, Kingham PJ, Gardiner NJ, Wiberg M, Terenghi G. 2006. Phenotypic and functional characteristics of mesenchymal stem cells differentiated along a Schwann cell lineage. Glia 54:840-849.

Couve A, Kittler JT, Uren JM, Calver AR, Pangalos MN, Walsh FS, Moss SJ. 2001. Association of $\mathrm{GABA}_{\mathrm{B}}$ receptors and members of the 14-3-3 family of signaling proteins. Mol Cell Neurosci 17: 317-328.

Dezawa M, Takahashi I, Esaki M, Takano M, Sawada H. 2001. Sciatic nerve regeneration in rats induced by transplantation of in vitro differentiated bone-marrow stromal cells. Eur J Neurosci 14:1771-1776.

di Summa PG, Kingham PJ, Raffoul W, Wiberg M, Terenghi G, Kalbermatten DF. 2009. Adipose-derived stem cells enhance peripheral nerve regeneration. J Plast Reconstr Aesthet Surg 63:1544-1552.

Friedenstein AJ, Chailakhyan RK, Latsinik NV, Panasyuk AF, KeilissBorok IV. 1974. Stromal cells responsible for transferring the microenvironment of the hemopoietic tissues. Cloning in vitro and retransplantation in vivo. Transplantation 17:331-340.

Garcia-Castro J, Trigueros C, Madrenas J, Perez-Simon JA, Rodriguez R, Menendez P. 2008. Mesenchymal stem cells and their use as cell replacement therapy and disease modelling tool. J Cell Mol Med 12:2552-2565.

Gimble JM, Katz AJ, Bunnell BA. 2007. Adipose-derived stem cells for regenerative medicine. Circ Res 100:1249-1260.

Ishikawa N, Suzuki Y, Dezawa M, Kataoka K, Ohta M, Cho H, Ide C. 2009. Peripheral nerve regeneration by transplantation of BMSCderived Schwann cells as chitosan gel sponge scaffolds. J Biomed Mater Res A 89:1118-1124.

Isomoto S, Kaibara M, Sakurai-Yamashita Y, Nagayama Y, Uezono Y, Yano K, Taniyama K. 1998. Cloning and tissue distribution of novel splice variants of the rat $\mathrm{GABA}_{\mathrm{B}}$ receptor. Biochem Biophys Res Commun 253:10-15.

Jiang L, Zhu JK, Liu XL, Xiang P, Hu J, Yu WH. 2008. Differentiation of rat adipose tissue-derived stem cells into Schwann-like cells in vitro. Neuroreport 19:1015-1019.

Jones KA, Borowsky B, Tamm JA, Craig DA, Durkin MM, Dai M, Yao WJ, Johnson M, Gunwaldsen C, Huang LY, Tang C, Shen Q, Salon JA, Morse K, Laz T, Smith KE, Nagarathnam D, Noble SA, Branchek TA, Gerald C. 1998. $\mathrm{GABA}_{\mathrm{B}}$ receptors function as a heteromeric assembly of the subunits $\mathrm{GABA}_{\mathrm{B}} \mathrm{R} 1$ and $\mathrm{GABA}_{\mathrm{B}} \mathrm{R} 2$. Nature 396: 674-679.

Kaupmann K, Huggel K, Heid J, Flor PJ, Bischoff S, Mickel SJ, McMaster G, Angst C, Bittiger H, Froestl W, Bettler B. 1997. Expression cloning of $\mathrm{GABA}_{\mathrm{B}}$ receptors uncovers similarity to metabotropic glutamate receptors. Nature 386:239-246.

Kaupmann K, Malitschek B, Schuler V, Heid J, Froestl W, Beck P, Mosbacher J, Bischoff S, Kulik A, Shigemoto R, Karschin A, Bettler B. 
1998. $\mathrm{GABA}_{\mathrm{B}}$-receptor subtypes assemble into functional heteromeric complexes. Nature 396:683-687.

Kingham PJ, Kalbermatten DF, Mahay D, Armstrong SJ, Wiberg M, Terenghi G. 2007. Adipose-derived stem cells differentiate into a Schwann cell phenotype and promote neurite outgrowth in vitro. Exp Neurol 207:267-274

Liske S, Morris ME. 1994. Extrasynaptic effects of GABA (gamma-aminobutyric acid) agonists on myelinated axons of peripheral nerve. Can J Physiol Pharmacol 72:368-374.

Liu X, Wang Q, Haydar TF, Bordey A. 2005. Nonsynaptic GABA signaling in postnatal subventricular zone controls proliferation of GFAPexpressing progenitors. Nat Neurosci 8:1179-1187.

Locke M, Windsor J, Dunbar PR. 2009. Human adipose-derived stem cells: isolation, characterization and applications in surgery. ANZ J Surg 79:235-244.

Lu P, Blesch A, Tuszynski MH. 2004. Induction of bone marrow stromal cells to neurons: differentiation, transdifferentiation, or artifact? J Neurosci Res 77:174-191.

Magnaghi V, Ballabio M, Cavarretta IT, Froestl W, Lambert JJ, Zucchi I, Melcangi RC. 2004. GABA $\mathrm{B}$ receptors in Schwann cells influence proliferation and myelin protein expression. Eur J Neurosci 19: 2641-2649.

Magnaghi V, Ballabio M, Consoli A, Lambert JJ, Roglio I, Melcangi RC. 2006. GABA receptor-mediated effects in the peripheral nervous system: a cross-interaction with neuroactive steroids. J Mol Neurosci 28:89-102.

Magnaghi V, Ballabio M, Camozzi F, Colleoni M, Consoli A, Gassmann M, Lauria G, Motta M, Procacci P, Trovato AE, Bettler B. 2008. Altered peripheral myelination in mice lacking GABAB receptors. Mol Cell Neurosci 37:599-609.

Magnaghi V, Procacci P, Tata AM. 2009. Chapter 15: novel pharmacological approaches to Schwann cells as neuroprotective agents for peripheral nerve regeneration. Int Rev Neurobiol 87:295-315.

Mahay D, Terenghi G, Shawcross SG. 2008a. Growth factors in mesenchymal stem cells following glial-cell differentiation. Biotechnol Appl Biochem 51:167-176.

Mahay D, Terenghi G, Shawcross SG. 2008b. Schwann cell mediated trophic effects by differentiated mesenchymal stem cells. Exp Cell Res 314:2692-2701

Mantovani C, Mahay D, Kingham M, Terenghi G, Shawcross SG, Wiberg M. 2010. Bone marrow- and adipose-derived stem cells show expression of myelin mRNAs and proteins. Regen Med 5:403-410.

Marcoli M, Candiani S, Tonachini L, Monticone M, Mastrogiacomo M, Ottonello A, Cervetto C, Paluzzi P, Maura G, Pestarino M, Cancedda R, Castagnola P. 2008. In vitro modulation of gamma amino butyric acid (GABA) receptor expression by bone marrow stromal cells. Pharmacol Res 57:374-382.

Neuhuber B, Gallo G, Howard L, Kostura L, Mackay A, Fischer I. 2004. Reevaluation of in vitro differentiation protocols for bone marrow stromal cells: disruption of actin cytoskeleton induces rapid morphological changes and mimics neuronal phenotype. J Neurosci Res 77:192-204.
Pfaff T, Malitschek B, Kaupmann K, Prezeau L, Pin JP, Bettler B, Karschin A. 1999. Alternative splicing generates a novel isoform of the rat metabotropic $\mathrm{GABA}_{\mathrm{B}} \mathrm{R} 1$ receptor. Eur J Neurosci 11:2874-2882.

Pinard A, Seddik R, Bettler B. 2010. GABA B $_{\text {r }}$ receptors: physiological functions and mechanisms of diversity. Adv Pharmacol 58:231-255.

Radtke C, Schmitz B, Spies M, Kocsis JD, Vogt PM. 2009. Peripheral glial cell differentiation from neurospheres derived from adipose mesenchymal stem cells. Int J Dev Neurosci 27:817-823.

Safford KM, Safford SD, Gimble JM, Shetty AK, Rice HE. 2004. Characterization of neuronal/glial differentiation of murine adipose-derived adult stromal cells. Exp Neurol 187:319-328.

Sanchez-Ramos J, Song S, Cardozo-Pelaez F, Hazzi C, Stedeford T, Willing A, Freeman TB, Saporta S, Janssen W, Patel N, Cooper DR, Sanberg PR. 2000. Adult bone marrow stromal cells differentiate into neural cells in vitro. Exp Neurol 164:247-256.

Schwarz DA, Barry G, Eliasof SD, Petroski RE, Conlon PJ, Maki RA. 2000. Characterization of gamma-aminobutyric acid receptor $\mathrm{GABAB}_{1 \mathrm{e}}$, a $\mathrm{GABAB}_{1}$ splice variant encoding a truncated receptor. J Biol Chem 275:32174-32181.

Strem BM, Hicok KC, Zhu M, Wulur I, Alfonso Z, Schreiber RE, Fraser JK, Hedrick MH. 2005. Multipotential differentiation of adipose tissue-derived stem cells. Keio J Med 54:132-141.

Sun BB, Chiu SY. 1999. N-type calcium channels and their regulation by $G_{A B A}$ receptors in axons of neonatal rat optic nerve. J Neurosci 19:5185-5194.

Terenghi G, Wiberg M, Kingham PJ. 2009. Chapter 21: use of stem cells for improving nerve regeneration. Int Rev Neurobiol 87:393-403.

Tohill M, Terenghi G. 2004. Stem-cell plasticity and therapy for injuries of the peripheral nervous system. Biotechnol Appl Biochem 40:17-24.

Tohill M, Mantovani C, Wiberg M, Terenghi G. 2004. Rat bone marrow mesenchymal stem cells express glial markers and stimulate nerve regeneration. Neurosci Lett 362:200-203.

Wei K, Eubanks JH, Francis J, Jia Z, Snead OC 3rd. 2001. Cloning and tissue distribution of a novel isoform of the rat $\mathrm{GABA}_{\mathrm{B}} \mathrm{R} 1$ receptor subunit. Neuroreport 12:833-837.

White JH, Wise A, Main MJ, Green A, Fraser NJ, Disney GH, Barnes AA, Emson P, Foord SM, Marshall FH. 1998. Heterodimerization is required for the formation of a functional $G_{A B A}$ receptor. Nature 396:679-682.

Woodbury D, Schwarz EJ, Prockop DJ, Black IB. 2000. Adult rat and human bone marrow stromal cells differentiate into neurons. J Neurosci Res 61:364-370.

Xu Y, Liu L, Li Y, Zhou C, Xiong F, Liu Z, Gu R, Hou X, Zhang C. 2008. Myelin-forming ability of Schwann cell-like cells induced from rat adipose-derived stem cells in vitro. Brain Res 1239:49-55.

Young SZ, Bordey A. 2009. GABA's control of stem and cancer cell proliferation in adult neural and peripheral niches. Physiology 24:171-185.

Zuk PA, Zhu M, Ashjian P, De Ugarte DA, Huang JI, Mizuno H, Alfonso ZC, Fraser JK, Benhaim P, Hedrick MH. 2002. Human adipose tissue is a source of multipotent stem cells. Mol Biol Cell 13:4279-4295. 